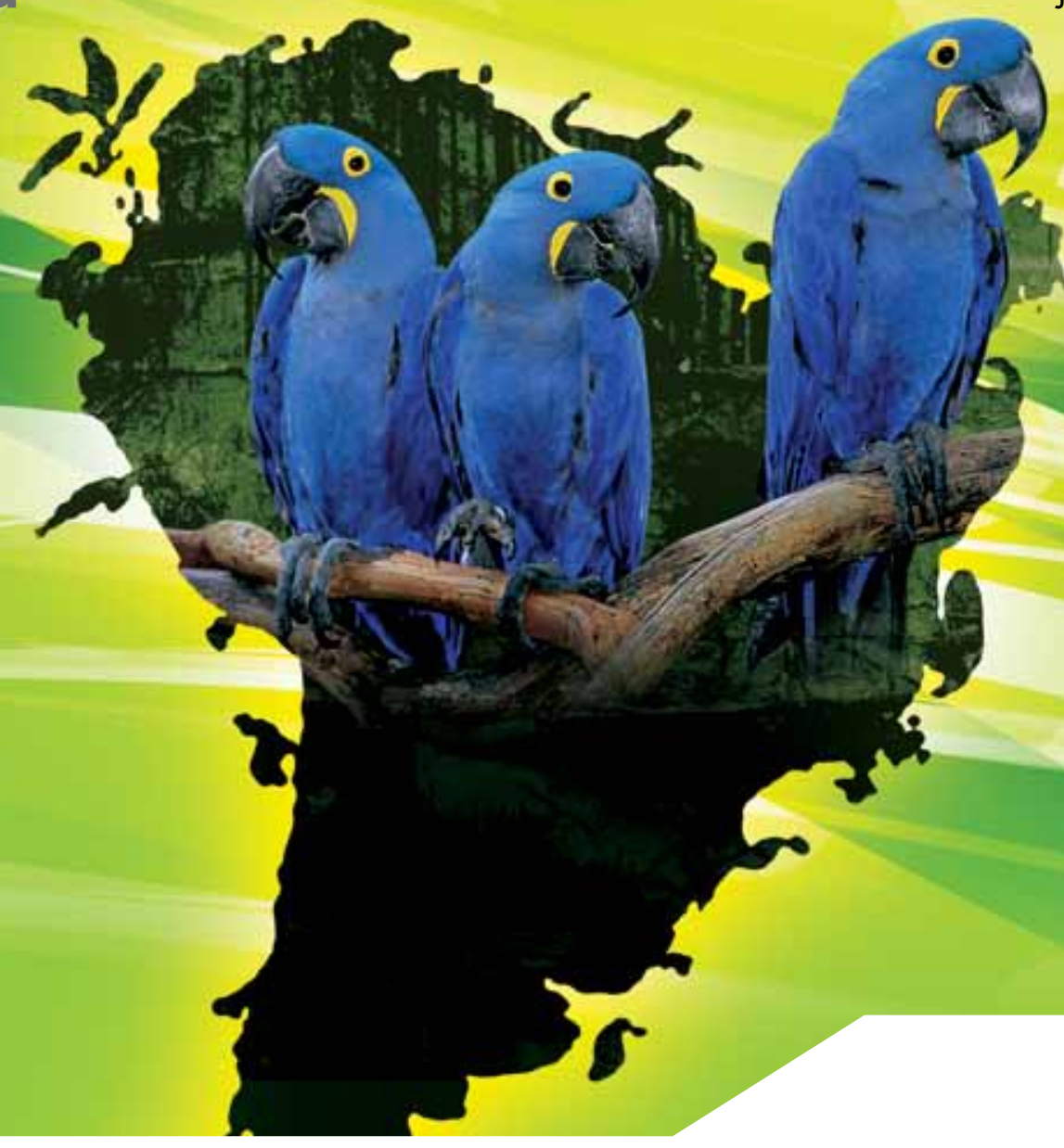

\title{
Reflexiones bioéticas acerca del tráfico ilegal de especies en Colombia*
}

$-106$ Bioética

> Julia Edith Carmona**

Santiago Eliécer Arango***
BIOETHICS REFLECTIONS ABOUT ILLEGAL TRADE OF SPECIES IN COLOMBIA

REFLEXÕES BIOÉTICAS SOBRE OTRÁFICO ILEGAL DE ESPÉCIES NA COLÔMBIA 


\section{RESUMEN}

El tráfico ilegal de especies, si bien es un problema a nivel mundial, para Colombia resulta particularmente grave, si se tiene en cuenta que es el segundo país megadiverso y, por tanto, una buena parte de la vida del Planeta se encuentra sustentada desde el suelo colombiano, es decir, el país es el segundo reservorio genético de la humanidad. Una de las mayores implicaciones de ésta problemática, consiste en la pérdida de la diversidad generada por una fuerte presión hacia la extinción de especies, esto unido al deterioro del hábitat por rupturas en las cadenas tróficas tienen implicaciones que se pueden considerar como catastróficas no sólo a nivel local, sino en un sentido más amplio, a nivel global.

\section{Palabras Clave}

Megadiversidad, conservación, endémico, hábitat, biocidio

\section{SUMMARY}

Illegal traffic of species is a well acknowledge International problem. In the of Colombia's It becomes particularly Ernst in that Colombia is the second mega-diverse country. Hence, a large part of life on Earth is placed within the Colombian territory, which makes of this country the second worldwide genetic reservoir for humankind. The most important implications of such a set of problems consist in the loss of diversity generated by the strong pressure on the extinction of species. This is united to the deterioration of the habitat due to the rupture of trophic chains which has serious consequences that can be considered as catastrophic not just on the local level but also in its largest worldwide level.

\section{Key Words}

Mega-diversity, conservation, endemical, habitat, biocide

\section{RESUMO}

O tráfico ilegal de espécies, ainda que seja um problema de nível mundial, é particularmente grave para a Colômbia se considerarmos que é o segundo país megadiverso e, portanto, uma boa parte da vida do Planeta se encontra sustentada em solo colombiano, ou seja, o país é o segundo reservatório genético da humanidade. Uma das maiores implicações desta problemática consiste na perda da diversidade, gerada por uma forte pressão para a extinção de espécies. Isto, unido à deterioração do habitat por rupturas nas cadeias tróficas, tem implicações que podem ser consideradas catastróficas não apenas em nível local como, em um sentido mais amplo, em nível global. 


\section{INTRODUCCIÓN}

El tráfico ilegal de especies es uno de los negocios más lucrativos del mundo, se calcula que se encuentra entre los tres más poderosos, conjuntamente con el narcotráfico y el tráfico de armas.

Colombia es un lugar propicio para que el tráfico ilegal de especies aumente considerablemente, debido a la megadiversidad que posee y al aumento considerable de pobreza que se tiene debido, entre otros factores, al conflicto armado, la falta de gobernabilidad y los coletazos del Neoliberalismo atroz, la enorme desigualdad social y los problemas consiguientes de inequidad, permitiendo abrir brechas inmensas entre la clase social pudiente y los empobrecidos.

Por tanto, lo que se pretende en este artículo es realizar una reflexión desde los principios de la Bioética, analizando el problema del tráfico ilegal de especies en Colombia, desde una perspectiva holística.

\section{EL HOMBRE NO RESPETA LAS OTRAS MANIFESTACIONES DE VIDA NO-HUMANAS}

El tráfico ilegal de especies es una actividad relacionada con el comercio de bienes derivados de las especies, que genera ciertas ganancias económicas, pero que infortunadamente está produciendo efectos nefastos en Colombia, tales como la pérdida de la biodiversidad el deterioro de hábitats, además de producir sufrimiento, dolor y muerte a especies que merecen el mismo respeto que un ser humano.

Por lo tanto, esta reflexión se inicia con el Antropocentrismo, que es la causa directa del comercio ilegal de especies. La visión antropocéntrica considera al ser humano como el centro del Planeta y de la creación en cuanto a importancia y supremacía frente a las demás especies. De acuerdo con la más antigua tradición Occidental, la naturaleza fue creada para que el ser humano "se enseñoreara" sobre ella. Esto es, para su propio placer y beneficio. En efecto, la creencia en Occidente de una escalera evolutiva en cuya cima se encuentra el ser humano, genera distorsiones frente al ambiente y todo ser vivo que en él habita. Esta visión conduce a modificar el territorio según las necesidades humanas y con ello desde luego a disponer de los otros seres vivos según la utilidad o el servicio que cumplan para nuestra especie.

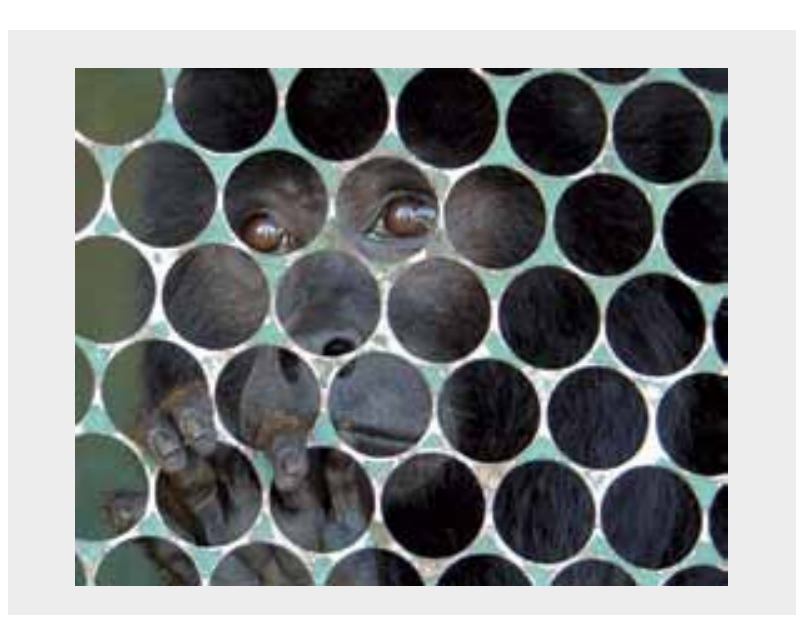

Copyrigth: Javier Fernando Pulido

El problema del tráfico ilícito de especies a nivel global, tiene repercusiones no solo en el plano ambiental sino que se extiende a la esfera social y económica, sin encontrar el eco necesario para generar medidas drásticas que frenen la problemática. Es así como, al leer el informe Geo-2000 del P.N.U.M.A.(Programa de Naciones Unidas para el Medio Ambiente), referenciado por Marcos (2001), donde se enuncian los principales problemas ambientales listados por expertos de más de 50 países del mundo, no se encuentra explícitamente mencionado el comercio ilegal de especies, aunque se podría considerar, desde luego, ligado a algunos de los problemas referenciados (pues es sabido, que ninguno de los problemas ambientales es aislado, sino que por el contrario, conforman una red, lo que agrava aún más la situación general del Planeta.

Sin embargo, sí se hace necesario hacer explícita la referencia al problema del tráfico ilegal de especies y resaltarlo conjuntamente con los demás problemas estos son:

El cambio climático, la escasez de agua dulce, la deforestación y desertificación, la contaminación del agua potable, la deficiente gobernabilidad, la pérdida de biodiversidad, el crecimiento y el movimiento de la población, los valores sociales cambiantes, la eliminación de desechos, los contaminación del aire, el deterioro del suelo, el mal funcionamiento de ecosistemas, la contaminación química, la urbanización. el agotamiento de la capa de ozono, el consumo de energía, la aparición de enfermedades, el agotamiento de recursos naturales, la inseguridad alimentaria, la perturbación del ciclo biogeoquímico, las emisiones industriales, la pobreza, las tecnologías de la información, las guerras y conflictos, 
la disminución a la resistencia a las enfermedades, los desastres naturales, las especies invasoras, la ingeniería genética, la contaminación marina, el agotamiento de las pesquerías, la circulación oceánica, la degradación de la zona costera, los desechos en el espacio, las sustancias tóxicas bioacumulativas, los efectos del Niño y subida del nivel del mar (cfr. Marcos, 2001. Pág. 89).

La referencia es necesaria si se le considera, a nivel mundial, como uno de los tres problemas más importantes, debería tener la misma importancia a nivel ambiental y no verlo únicamente como un problema ilegal que mueve enormes cifras, sino que además, compromete la vida del Planeta y con ella desde luego la vida humana.

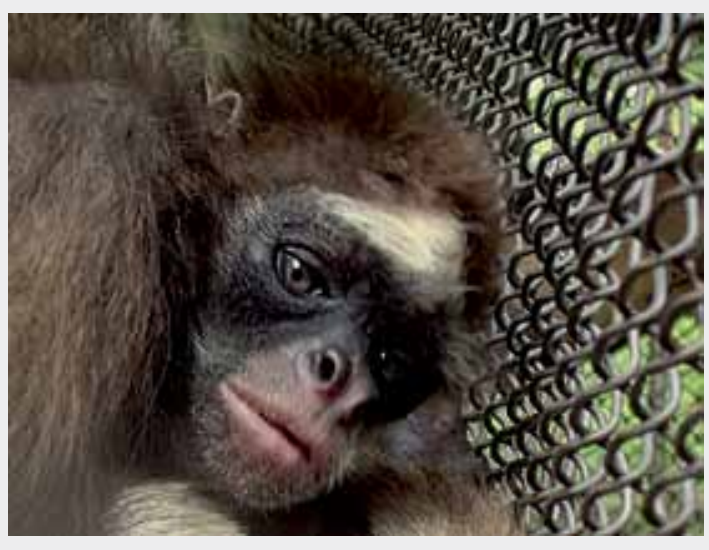

Copyrigth: Javier Fernando Pulido

\section{ANTROPOCENTRISMO ATRÓZ}

Como afirma Botkin (1993), hasta la Revolución Industrial, en Occidente, las dos visiones principales sobre la naturaleza consistían en: la de la naturaleza orgánica y la de la naturaleza como creación divina. La de la naturaleza creada por una divinidad, se consideraba perfectamente ordenada y estable; alcanzaba una situación de constancia que al ser alterada retornaba nuevamente a esa condición inicial considerada constante y buena. Esa constancia, no permitía tener una visión biocéntrica o ecocéntrica, sino, que alimentaba de una forma voraz la superioridad humana frente al hábitat y todo aquello que allí se encontrara; por lo tanto la transformación del ambiente con fines exclusivamente antropocéntricos no sólo se veía como una acción buena, sino que además era deseable.

Marcos (2001) hace una referencia más conciliadora respecto a la posición del cristianismo:
“En los textos bíblicos se encuentran sugerencias para fundar una ecología de la responsabilidad para con las futuras generaciones... pues nada, según el cristianismo nos pertenece en términos absolutos, sino que sólo administramos -y hemos de hacerlo prudentemente- los bienes que Dios nos confía" (pág. 67).

Sin embargo, ésta no es la interpretación que históricamente se ha hecho de la naturaleza, quizás porque el hecho de que la misma biblia mencione que el hombre fue hecho a imagen y semejanza de Dios, ya le confiere un estatus de poder sobre las demás criaturas, tornándolo incluso miope y egocéntrico, hasta el punto incluso de considerar a la mujer inferior al hombre y como símbolo de maldad y brujería, esto último concretamente en la historia de la Santa Inquisición.

Esto va unido, además, a la interpretación popular de la biología que se impartía en los años setentas e incluso los ochentas, donde se enseñaba la existencia de tres reinos en la naturaleza: el animal, el vegetal y el mineral. Según la Real Academia de la Lengua, reino es: (del lat. regnum), "Territorio o Estado con sus habitantes sujetos a un Rey", en el caso particular de la naturaleza, el rey es el hombre y los habitantes las otras manifestaciones de vida no-humanas, es decir, los animales y los minerales, que se encuentran sometidos a un rey.

De tal suerte, que la historia tiene su razón, únicamente en virtud y para favorecimiento del ser humano; por consiguiente, todo culmina con él. Nada tiene valor intrínseco, ninguna otra cosa posee alteridad y sentido sin él. Es más, la comprensión tradicional del ser humano fue la imagen varonil y viril en desmedro del reconocimiento de la importacia del género femenino.

Todos los seres están a su disposición en orden a realizar sus deseos y proyectos. Él se siente por encima de las cosas y no al lado y con las cosas. Se imagina como un punto aislado y único, fuera de la naturaleza y por encima de ella. Con arrogancia puede dispensar a respetarla, Boff (1996), citado por Cely (2007).

Posteriormente, en particular gracias a las contribuciones de Whitakker, se enseñó una clasificación diferente de los organismos, en que se agrupan en cinco grandes categorías o reinos: El reino de las Monera (comprende a los organismos más pequeños y más simples, las bacterias y sus parientes); el reino de los Protistas (son los eucariotas como las amebas, los 


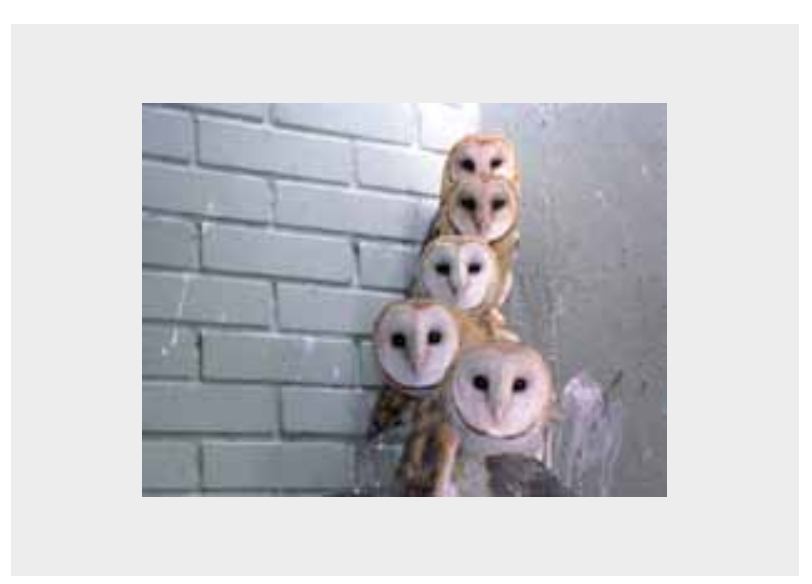

Copyrigth: Javier Fernando Pulido

paramecios y las diversas formas de algas); el reino fungi (constituido por los hongos, los mohos, las levaduras y las setas); el reino de las plantas; y el quinto grupo lo constituye el reino animal, Curtir \& Barnes (1994).

Con la clasificación de los cinco grupos, si bien se sigue hablando de reinos, el ser humano pertenece al reino animal y, por tanto, la superioridad desde la cual hace referencia el catolicismo le sede el paso a una igualdad en el sentido biológico más amplio y coloca al ser humano en el mismo escalón con los otros animales. Sin embargo, esta mirada biocéntrica no comienza a cobrar importancia sino hasta hace unos pocos años, cuando el ser humano comienza a darse cuenta del deterioro ambiental causado exclusivamente por la acción humana.

A finales del siglo $X X$, sobre la base de la bioquímica, Carl Woese y sus colaboradores, propusieron un nuevo sistema de clasificación, de tres dominios, en donde se agrupan los organismos a partir de las diferencias entre ciertas secuencias genéticas y sus componentes bioquímicos, se tiene entonces que algunos moneras, como los metanógenos, los que toleran el ácido, y las bacterias halóficas, han sido clasificados como Archea (o arqueas); los cuatro reinos de los eucariotas se incluyeron en el dominio Eukarya, debido a su origen evolutivo común; el tercer dominio es Bacteria, Margulis \& Dolan (2009).

La clasificación de los tres dominios es la que actualmente se está enseñando en Colombia, en algunos de los colegios. Lo que resulta interesante de esta forma de agrupar a los organismos, es que el ser humano está ahora en un grupo más grande que incluye: animales, plantas y hongos, es decir, el ser humano se muestra como un accidente evolutivo y no como algo necesario y predestinado a surgir en el escenario de la vida de la Tierra.

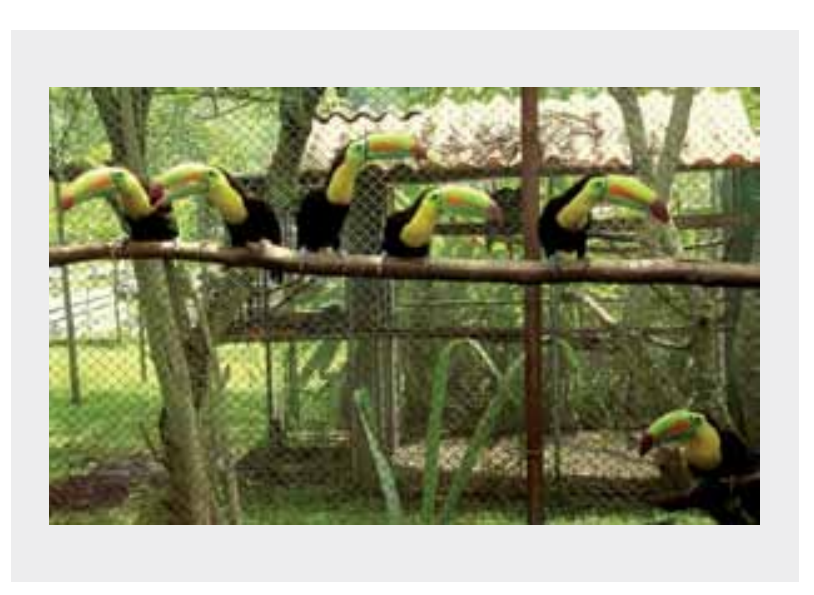

Copyrigth: Javier Fernando Pulido

\section{¿LAS OTRAS MANIFESTACIONES DE VIDA TIENEN DERECHOS?}

El 23 de Septiembre de 1977 en la ciudad de Londres (Inglaterra), se realizó la discusión sobre los Derechos de los Animales, la cual se proclama el 15 de Octubre de 1978 aprobada por la Organización de las Naciones Unidas para la Educación, la Ciencia y la Cultura (UNESCO) y posteriormente por la Organización de Naciones Unidas (ONU).

\section{El artículo 1 proclama:}

Todos los animales nacen iguales ante la vida y tienen los mismos derechos a la existencia. Esa igualdad ante la vida, (no se hace diferencia con respecto a la vida humana) pone al ser humano al mismo nivel de cualquier animal, por tanto, el hecho de que alguna especie en particular no resulte del agrado del ser humano, bien sea por su no utilidad o porque no representa ningún tipo de beneficio, no la excluye de este primer derecho.

\section{Por su parte, el artículo 2 afirma:}

a. Todo animal tiene derecho al respeto.

b. El hombre, en tanto que especie animal, no puede atribuirse el derecho de exterminar a los otros animales o de explotarlos violando ese derecho. Tiene la obligación de poner sus conocimientos al servicio de los animales.

c. Todos los animales tienen derecho a la atención, a los cuidados y a la protección del hombre.

Pues bien, estos derechos claramente son violados con el tráfico ilegal de especies silvestres. Pero además, no se han cumplido a cabalidad pese a existir desde 1978. Si se hace memoria, algunas Facultades de Medicina, por lo 
menos hasta finales del siglo XX, tenían una materia de carácter obligatorio, llamada cirugía experimental; en ella, los estudiantes iniciaban sus prácticas cosiendo en tela, de tal forma que adquirieran la destreza de la sutura (herramienta que utilizarían los médicos especializados en cirugía), de esta primera aproximación se pasaba a la práctica en una visera de animal (usualmente de vaca). Esta actividad consistía en dividir la visera en dos y luego suturarla para posteriormente someterla a la prueba de "la llave de agua", la cual si no tenía filtraciones (a la manera de una manguera rota) se consideraba superada esta etapa, para culminar con la prueba definitiva que permitía o bien aprobar la materia o reprobarla, ésta consistía en la cirugía de "perros". Frecuentemente se utilizaban perros callejeros que se tenían en una especie de perrera y se asignaban por grupos de estudiantes; la actividad consistía en anestesiar al perro, abrirlo, dividir alguna de sus viseras en dos para luego volverlas a unir y finalmente suturar. Si el perro al otro día estaba vivo, el grupo pasaba la asignatura de lo contrario debían repetir. Esta práctica conllevaba además, un elemento adicional y era el hecho de no contar con un espacio lo suficientemente amplio como para tener el número adecuado de perros y, por tanto, el animal que había estado sometido a dicha intervención tenía una alta probabilidad de volver a participar en la cirugía experimental a los pocos días, cuando aún no se había recuperado totalmente de la primera.

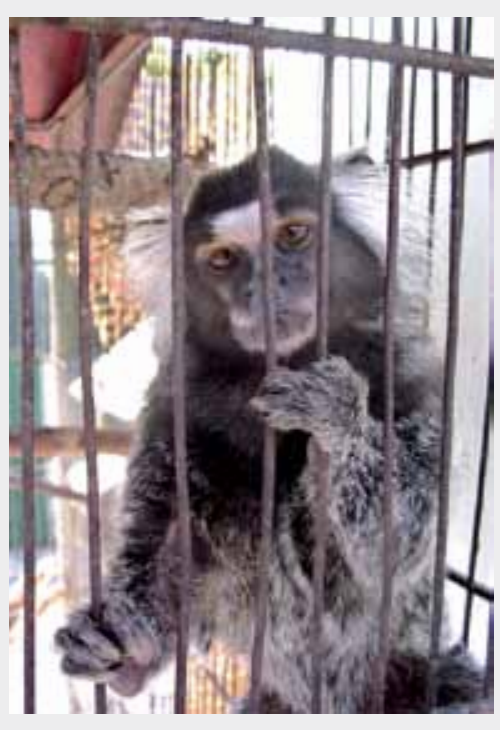

Copyrigth: Javier Fernando Pulido

\section{El artículo 3 afirma:}

a. Ningún animal será sometido a malos tratos ni actos crueles.

b. Si es necesaria la muerte de un animal, ésta debe ser instantánea, indolora y no generadora de angustia.

Con respecto a estos derechos, Colombia por ejemplo, es uno de los países en los que aún se práctica el arte de la tauromaquia: Se tienen plazas en ciudades importantes como: Bogotá, Manizales, Cali, Medellín y Cartagena. Esto, para poner un ejemplo de una actividad legalmente aceptada, donde el dolor, el sufrimiento y la muerte de un animal no tienen ningún carácter punitivo. Bien, respecto al tráfico ilegal, la muerte, sufrimiento y estrés al que se somete a estos animales será narrada con detalles, en una entrevista realizada a Javier Pulido, médico veterinario especializado en animales silvestres.

\section{Estimado Doctor, Javier Pulido:}

- ¿Deseo que nos cuentes a grandes rasgos cómo es la manipulación que se le hace a los individuos capturados desde su hábitat, hasta al momento de entrega al primer intermediario?

“Estimado Santiago, quiero agradecerle por la confianza que me brinda al concederme esta entrevista, ya que es una linda oportunidad de denunciar sobre los abusos y, por consiguiente, el sufrimiento que se le causa a individuos inocentes, y máxime en el escenario de la Bioética que se encuentra en mora de reflexionar sobre este tema, que es una problemática que aqueja a todos los países que se encuentran en vía de desarrollo y que tienen una gran diversidad biológica, como es el caso de nuestro querido país, Colombia.

Antes de responderle en detalle su pregunta, es fundamental realizar un pequeño recuento histórico sobre los antecedentes del tráfico ilegal de especies, dicho aporte nos puede dar ciertas claridades sobre sus inicios, y sobre el porqué dicha práctica es muy difícil de controlar.

El problema de la tenencia de animales silvestres, es una práctica que se realiza desde el comienzo de los tiempos; en Occidente, los primeros fueron los ingleses en los años 1800, cuando invadieron países del África y Asia, comenzaron a llevar animales silvestres; en América Latina los primeros pasos se dieron de manera muy sutil en los indígenas, aclarando que no tenían los animales para poder mostrar o exhibirlos, ya que ellos tienen una manera de ver el medio ambiente con más respeto, y se preocupan por tener una vida más armónica con su entorno. 


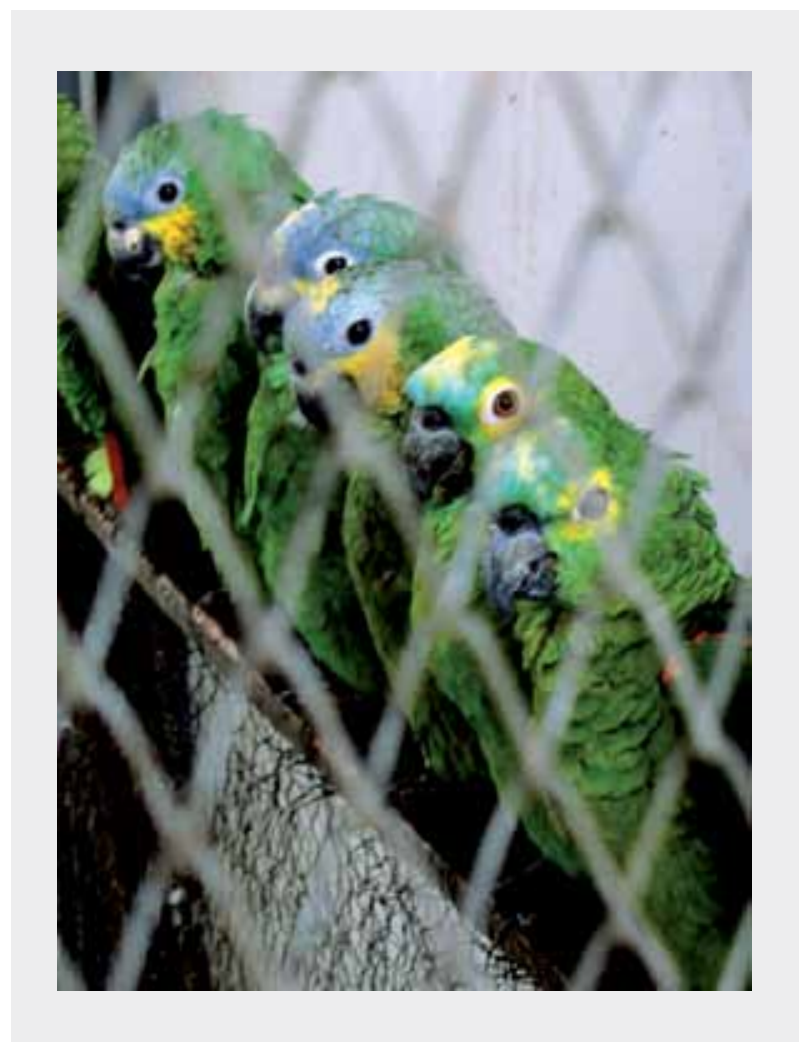

Copyrigth: Javier Fernando Pulido

Pero cuando llegaron los portugueses y españoles, al continente Americano llevaron aves y mamíferos, proliferando las aves por su facilidad, y en especial los loros, guacamayas, por su belleza y porque tenían la capacidad de repetir palabras y frases.

En el siglo XX se cazaban los animales para utilizar las pieles, por ejemplo, en América del Sur, se cazaron muchas nutrias; más tarde se fomentó la caza como un espacio deportivo, esta práctica tuvo mucho auge en los Estados Unidos, en América del Sur también se practicó la caza como deporte, pero no tuvo muchos seguidores, la práctica de la caza era con el fin de poner a prueba las municiones, por ejemplo, en una práctica se podía cazar hasta 400 caimanes, en un solo día.

Después de los años cincuenta, a nivel mundial, se comenzó a ver la caza como algo negativo, por lo tanto se optó por la no-caza de animales silvestres, pero se reemplazó por la tenencia de animales exóticos como mascotas, ya que esta práctica muestra poder económico, y status a los "dueños de especies exóticas", ahora bien, si nos remontamos a Colombia, los indígenas tenían crías de miquitos, loros, etc. y estas prácticas fueron aprendidas por los colonos.
Es importante que se conozca cómo se extraen los animales de sus hábitats, para ver si generamos una mirada diferente al tráfico ilegal de especies, y así generar cierto tipo de desmotivación a los potenciales compradores. Por ejemplo, hablemos de las aves, ellos hacen sus nidos en los árboles, el colono o indígena, coge un pichón o dos, dependiendo de la especie, en muchas de las ocasiones la madre ataca al recolector, y éste lo que hace es asesinar a la madre; pero además puede suceder que durante este proceso se le pueda caer uno o varios polluelos quitándoles la vida instantáneamente; suponiendo que el recolector tiene la misión de recoger 100 polluelos, dicho recolector no tiene el conocimiento básico para darle el alimento apropiado, por lo tanto le da cualquier papilla a los animales, perdiendo varios animales por hambre, y en otros casos, los animales mueren por bronco aspiración ya que les suministran mucho alimento, ocasionando asfixia y la muerte. Se calcula por lo tanto,que de cada 100 pichones o polluelos, el recolector le lleva al primer intermediario 10 animales; este intermediario le entrega una miseria de dinero al colono o al indígena, por lo tanto ellos se esmeran por recolectar el máximo de especies con tal de recoger dinero, se calcula que cada colono o indígena recogen unos mil ejemplares para poderle llevar al primer intermediario unos cien animales, ya que los otros novecientos han fallecido durante el transporte por las causas ya mencionadas, por lo tanto imagínese el daño que se le ocasiona al medio ambiente y el sufrimiento a que son sometidos dichos animales.

Este primer intermediario los alimenta muy mal, viéndose claramente en el pico ya que se encuentra cuarteado, o más largo que lo normal, ya que el animal no ha tenido la oportunidad de utilizar de manera adecuada su pico, y no sufre ningún tipo de desgaste, pero además les pintan los plumones para que se vean los pichones de una edad adecuada.

Aclarando que muchos de estos primeros intermediarios tienen contactos con compradores internacionales que les pueden dar por cada ejemplar varios millones de pesos, por ejemplo, un águila puede costar 50 a 80 millones de pesos.

Ahora hablaremos de la manera como son transportados a otras ciudades o países. Por ejemplo, al loro le dan aguardiente para atontarlo, y así tranquilizarlo, de tal manera que si la policía detiene el automóvil, el animal no va a emitir ningún tipo de sonido, estos animales son metidos en tubos de PVC, con pequeños huecos para que le permita respirar, pero los meten de una manera brusca 


\section{En el siglo XX se cazaban los animales para utilizar las pieles, por ejemplo, en América del Sur, se cazaron muchas nutrias; más tarde se fomentó la caza como un espacio deportivo, esta práctica tuvo mucho auge en los Estados Unidos, en América del Sur también se practicó la caza como deporte, pero no tuvo muchos seguidores.}

como si fuera cualquier objeto entre ropas, o cachivaches viejos, las serpientes o culebras son metidas en medias veladas y enrollados alrededor de la cintura o en las piernas; los primates también son sometidos a maltratos, pero gracias a su inteligencia es algo más complejo, a ellos los anestesian y los meten en cajitas angostas ocasionando la muerte a un $90 \%$ de los ejemplares.

Como conclusión, cada animal es maltratado, ocasionándole mucho sufrimiento, ¿Si cada persona es consciente que detrás de ese loro u otro animal que se tiene en casa murieron varios? Creo que ya no serían tan apetecidos.

Definitivamente el tener una especie silvestre en casa, es un acto egoísta, ya que se convierte en un trofeo, a costa del sufrimiento del individuo; dicho animal tarde o temprano va a morir ya sea por alguna enfermedad o por mala nutrición; el "dueño del animal" a lo mejor puede tener la mejor intención de proporcionarle los mejores medios para que el animal posea el máximo de bienestar, pero esto nunca se va a lograr en plenitud, debido a que la Medicina Veterinaria todavía está incipiente en este tipo de conocimientos, ya que es un mundo muy amplio y complejo, aclarando que en la actualidad existen avances significativos y en ocasiones se logra que el animal viva muy bien, pero detrás de la vida de este animal murieron centenares de individuos que también fueron sometidos a un tratamiento indigno.

\section{El artículo 4 afirma:}

a. Todo animal perteneciente a una especie salvaje, tiene derecho a vivir libre en su propio ambiente natural, terrestre, aéreo o acuático y a reproducirse.

b. Toda privación de libertad, incluso aquella que tenga fines educativos, es contraria a este derecho.

\section{El artículo 8 afirma:}

a. La experimentación animal que implique un sufrimiento físico o psicológico es incompatible con los derechos del animal, tanto si se trata de experimentos médicos, científicos, comerciales, asi como toda otra forma de experimentación.

Al respecto, en algunas Facultades de Psicología, a finales del siglo XX, se hacia experimentación con ratas de laboratorio (rata albina); uno de los experimentos consistía en enseñar a la rata a presionar palanca para obtener alimento; para ello, se dejaba a la rata un fin de semana con un mínimo de alimento (siempre tenía a su disposición una botella de agua), lo que permitía que el día lunes, estuviera en las condiciones óptimas para el entrenamiento (se encontraba hambrienta). Se procedía entonces a poner la rata en una caja de experimentación la cual contenía la palanca a presionar y un orificio por donde bajaban las pequeñas bolitas de comida que se le daban en la medida que presionaba la palanca. A esto le seguía la exigencia de una tasa de respuestas cada vez mayor, es decir, la 
Es evidente que los animales experimentan dolor; basta con asistir a una corrida de toros y mirar a los ojos al toro que está en el ruedo, se siente, se duele y hasta llora. Es fácil asistir a estos eventos sin entender el dolor de un ser vivo, pues el efecto del licor impide que los sentidos funcionen adecuadamente. primera bolita de comida se le suministraba si se acercaba a la palanca, esto le generaba a la rata una asociación de que en ese lugar había comida, luego accidentalmente presionaba la palanca y el movimiento permitía establecer más claramente la asociación, se seguía de esta forma con el entrenamiento y se le exigía luego, por ejemplo, la presión de cinco veces la palanca para obtener una bolita de comida, luego diez, y así sucesivamente hasta completar el entrenamiento, teniendo la certeza de que la rata asoció la palanca con el alimento. Una vez concluida esta primera fase, si se trabajaba, por ejemplo, la desesperanza aprendida, el paso a seguir, era proporcionar a la rata ya no comida, sino un choque eléctrico de cinco miliamperios, lo cual le generaba el suficiente miedo y estrés para no volver a presionar la palanca (por más hambre que tuviera), comprobándose así, la desesperanza aprendida.

\section{El artículo 11 afirma:}

Todo acto que implique la muerte de un animal sin necesidad es un biocidio, es decir, un crimen contra la vida.

\section{El artículo 12 afirma:}

a. Todo acto que implique la muerte de un gran número de animales salvajes es un genocidio, es decir, un crimen contra la especie.

\section{El artículo 14 afirma:}

a. Los derechos del animal deben ser defendidos por la ley, como lo son los derechos del hombre.

Los derechos de los animales mencionados anteriormente, se consideran altamente pertinentes para la reflexión bioética sobre el tráfico ilegal de especies en Colombia.

\section{LOS ANIMALES SIENTEN DOLOR}

Singer (1999) hace una referencia particular con respecto al dolor que sienten los animales. El texto lo toma de Serjeant (1969), quien afirma:

"Cada brizna de evidencia basada en los hechos apoya la tesis de que los vertebrados mamíferos más desarrollados experimentan sensaciones de dolor al menos tan agudas como las nuestras. Decir que sienten menos porque son animales inferiores es un absurdo; se puede demostrar fácilmente que muchos de sus sentidos son más agudos que los nuestros: la agudeza visual en ciertas aves, el oído en la mayoría de los animales salvajes y el tacto en otros; en la actualidad, estos animales dependen más 


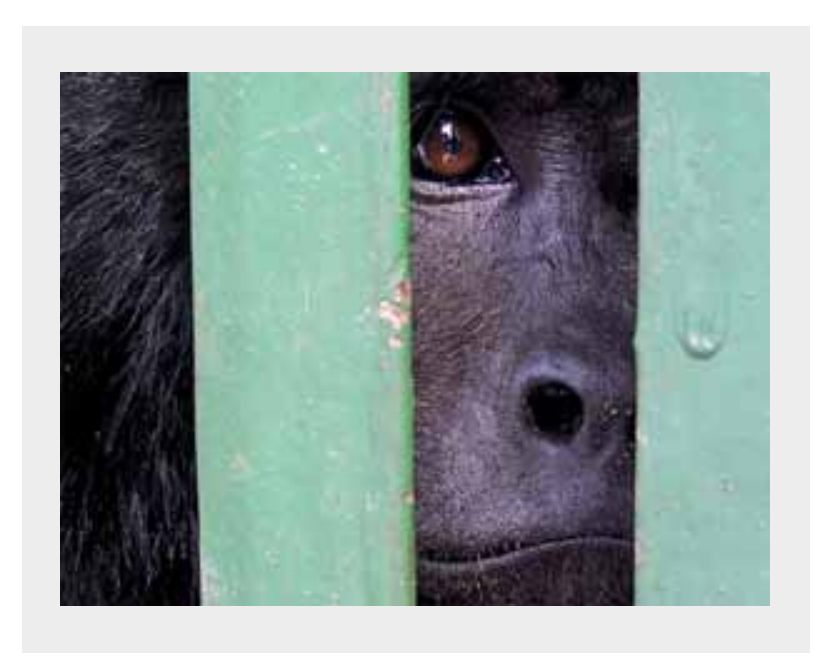

Copyrigth: Javier Fernando Pulido

que nosotros del conocimiento más completo posible de un medio hostil. Aparte de la complejidad de la corteza cerebral (que no percibe dolor directamente), sus sistemas nerviosos son casi idénticos a los nuestros y sus reacciones ante el dolor extraordinariamente parecidas, aunque carentes (según la información de que disponemos) de connotaciones filosóficas y morales. El elemento moral es de sobra evidente, ante todo en forma de miedo y cólera".

Es evidente que los animales experimentan dolor; basta con asistir a una corrida de toros y mirar a los ojos al toro que está en el ruedo, se siente, se duele y hasta llora. Es fácil asistir a estos eventos sin entender el dolor de un ser vivo, pues el efecto del licor impide que los sentidos funcionen adecuadamente. Al parecer la anestesia que es impartida a los animales que son objeto del tráfico ilegal, es necesaria igualmente para poder tolerar un arte como la tauromaquia. Ejemplos similares pueden mencionarse a propósito de divertimentos como las peleas de gallos, las peleas de perros (habitualmente Pitbulls), y otras manifestaciones violentas hacia los animales.

\section{NUEVO PARADIGMA DE LA BIOÉTICA EN PRO DEL ANTROPOCENTRISMO}

Pero es la Bioética desde sus comienzos, es decir, desde que Potter comenzó a pensarla, vislumbró esta disciplina como una: "verdadera dinámica e interacción entre el ser humano y el ambiente", él mismo habla de una ética de la Tierra, Garzón, (2002). Es por esto que a Potter se le considera internacionalmente como el padre de la ética con raigambre ambiental que, en perspectiva global, vela por el cuidado de la vida como opción fundamental, Cely (2007). Por lo tanto la Bioética se convirtió en sus comienzos y en la actualidad en un nuevo paradigma, con una mirada inversa, es decir, del antropocentrismo al biocentrismo, colocando al ser humano como una especie más dentro de esta enramada de especies que se encuentran habitando la nave espacial llamada Tierra, con la aclaración de que el hombre posee ciertas características que lo hacen diferente a las demás especies, debido a que es la única especie que se ha preguntado por su entorno, encontrar respuestas y transformarlo, creando culturas que se adaptan a la situación geográfica supliendo sus necesidades, mientras que otras manifestaciones de vida no-humanas, poseen un "pool genético" que le indica su comportamiento, y a su vez, aprenden otras maneras de comportarse, lo que llaman los etólogos, comportamiento adquirido.

Según las consideraciones anteriores, la ética ecológica hace referencia formalmente al ser humano $y$, en ese sentido, es siempre antropocéntrica, materialmente ella tiene como contenido la vida y, por tanto es biocéntrica. Al ser ética, ella sólo se le puede atribuir a seres humanos, porque sólo ellos pueden desarrollar acciones intencionadas, mas en cuanto ecológica, está referido al

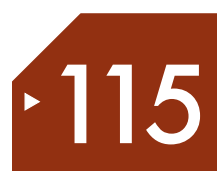
dinamismo vital que transcurre en la comunidad biótica. Por tanto las dos categorías básicas de la ética ecológica son la actitud humana de cuidado frente a la fragilidad de la vida y el dinamismo que hermana seres vivos interdependientes de una comunidad biótica, Junges (2004), citado por Cely (2007).

\section{MARCO HISTÓRICO DEL COMERCIO DE FAUNA SILVESTRE Y EL TRÁFICO ILEGAL EN COLOMBIA}

El tráfico ilegal de fauna silvestre en Colombia, tiene graves efectos sobre la megadiversidad, tales como la erosión genética, la reducción en los tamaños de las poblaciones y la vulnerabilidad frente a los procesos de extinción. El término fauna silvestre hace referencia a: el conjunto de especies de fauna de todos los taxones y ambientes, nativas o migratorias, cuyo origen y evolución se encuentran dentro del territorio nacional, que no han sido objeto de mejoramiento genético y que en los niveles de especie o variedad mantienen o mantuvieron al menos una población viable de existencia libre (no en cautiverio) en sus hábitats naturales formando parte integral de los procesos evolutivos y ecológicos. No se 


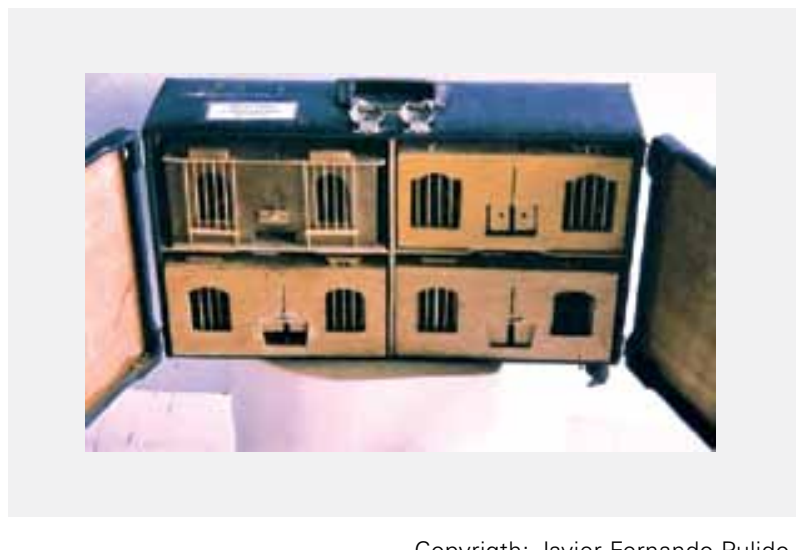

Copyrigth: Javier Fernando Pulido

consideran vida silvestre las especies que han sido modificadas genéticamente ni las especies que provienen de la introducción voluntaria o involuntaria del agente humano y que en la actualidad están presentes o establecidos en el país. Los bienes o productos derivados de la fauna que se comercian incluyen especímenes vivos, sus partes, o sus derivados, CGR (2005), citado por Mancera \& Reyes (2008).

El tráfico ilegal de especies silvestres en Colombia, afecta a 234 especies de aves, 76 de mamíferos, 27 de reptiles y 9 de anfibios. En cuanto a la flora, especies con un alto valor comercial a nivel nacional e internacional, como por ejemplo: el cedro y el guayacán, así como plantas ornamentales como: el cactus y las orquídeas son altamente apreciadas por coleccionistas privados, lo que aumenta la problemática de pérdida de la biodiversidad. Este comercio ilegal generó que

el Ministerio del Ambiente y Desarrollo Sostenible, liderara campañas para la prevención y control al tráfico ilegal de especies silvestres desde el 2002, la cual se encuentra orientada a la atención de todas aquellas actividades ilícitas de aprovechamiento de especímenes silvestres, entendiendo como tales a todos los organismos de la diversidad biológica ya sean vivos, muertos o a cualquiera de sus productos, partes o derivados, (tomado de la página del Ministerio de Ambiente y Desarrollo).

El Instituto Humboldt, muestra claramente las acciones que se están implementando en Colombia con respecto al tráfico ilegal de especies silvestres. Se evidencia, por ejemplo, que el comercio ilegal de animales silvestres es considerado un delito penado de 2 a 5 años de cárcel y con multas de hasta 10 salarios mínimos legales mensuales vigentes.

\section{INCAUTACIONES Y CAPTURAS ENTRE EL AÑO 2010 Y 2011}

\section{Incautaciones 2010}

\begin{tabular}{|c|c|}
\hline Incautaciones y captura & $\begin{array}{c}\text { Enero a Diciembre } \\
\text { de 2010 }\end{array}$ \\
\hline Flora (Unidad) & 407.816 \\
\hline Aves & 15.468 \\
\hline Mamíferos & 3.573 \\
\hline Reptiles & 3.573 \\
\hline Maderas (m3) & 402.056 \\
\hline Pescados & 5.579361 \\
\hline Personas capturadas & 2332 \\
\hline
\end{tabular}

\section{Incautaciones 2011}

\begin{tabular}{|c|c|}
\hline Incautaciones y captura & Enero a Abril de 2011 \\
\hline Flora (Unidad) & 110.408 \\
\hline Aves & 4.685 \\
\hline Mamíferos & 1.459 \\
\hline Reptiles & 30.700 \\
\hline Maderas (m3) & 23.383 \\
\hline Pescados & 696 \\
\hline Personas capturadas & 1.342 \\
\hline
\end{tabular}

\section{CONCLUSIONES}

Sin duda, una de las causas del aumento considerable del tráfico ilegal de especies en Colombia se debe a dos razones fundamentales: La primera razón a su escandalosa pobreza, y la segunda razón a su prestigiosa ubicación geográfica que lo hace uno de los paises más megadiversos del planeta en cuanto a su biodiversidad "Colombia tiene el privilegio de poseer una de las faunas más variadas del mundo, debido en parte a su ubicación ecuatorial y a la compleja topografía del país, aunque otra variedad de factores probablemente favorecen también esta alta biodiversidad. A pesar del limitado conocimiento que se tiene de la fauna y la flora de colombiana, puede señalarse que es el país con más especies de aves, crocodrílidos, dantas, orquídeas y ranas que cualquier otro país del mundo y es uno de los mayores poseedores de especies de serpientes, lagartijas, 
peces y plantas angiospermas. Colombia, es por lo menos, el cuarto país en el mundo respecto al número de mamíferos registrados con 471 especies" (Alberico, et al., 2000:22, Citado por Deffler 2003)".

Por lo tanto, se puede afirmar que el tráfico ilegal de especies es la resultante de varias aristas. La primera arista es la gran pobreza que se vive en Colombia, la segunda arista es la situación privilegiada que tiene Colombia de ser un país Megadiverso, por consiguiente posee especies anheladas por muchos extranjeros dispuestos a pagar sumas cuantiosas de dólares, y la tercera arista qué es la más fuerte de todas, es la concepción que el hombre ha tenido acerca de la naturaleza, en dónde las otras especies son vistas cómo inferiores, sin derechos; ésta manera de vislumbrar la naturaleza lo ha llevado a tener una postura arrogante, depredadora y, por supuesto, antropocentrista, llevándo al Homo sapiens sapiens a su auto destrucción paulatina.

Mientras el hombre no vea el todo, cómo un escenario sagrado, es decir el respeto a toda manifestación de vida, independientemente sí la especie es más o menos evolucionada, según los canones de la Biología, vamos a tener un planeta enfermo, mientras el hombre no deje su soberbia y acepte que dependemos de la naturaleza, y que todo ser vivo por insignificante que parezca, merece el derecho a la vida, ya que dicho ser contribuye a mantener ese magnífico equilibrio ecológico.

Por lo tanto es muy importante una verdadera Educación Ambiental, y cuando me refiero a una verdadera Educación Ambiental, quiero decir a una estrategía pedagógica que se salga de los canones tradicionales como las prácticas del reciclaje, recolección de las basuras, etc., que son muy importantes, pero veo la urgente necesidad de dar un virage a las tradicionales prácticas, y utilizar muchas herramientas que nos suministra la Bioética, que permita una reflexión más profunda sobre la urgente necesidad de ver las otras manifestaciones de vida como organismos indispensables para la plenificación y desarrollo del ser humano, es decir, tener un ethos que lleve a la humanidad al reconocimiento del otro, que lo invita a tener posturas cotidianas más sanas que nos permita contaminar menos en nuestro diario vivir.

Quiero resaltar la importancia de la Educación Ambiental en aras al tema del tráfico ilegal de especie, ya que si el hombre, en este caso el habitante colombiano, tuviese una mirada diferente, cómo la sacralidad de la vida y el respeto máxime a cualquier manifestación de vida, llámese humana o no, de pronto el ciudadano del común evitaría realizar este tipo de prácticas nocivas para el medio ambiente en general, que atentan contra el bienestar de las especies traficadas y por supuesto peligra la supervivencia del hombre, debido a que la práctica del tráfico ilegal de especies afecta directamente a la biodiversidad del país, originando desequilibrios medio ambientales y dichos desequilibrios hacen que la Madre Tierra se enferme.

\section{NOTAS}

1 Pontificia Universidad Javeriana. Email: jecarmona@javeriana.edu.co

2 Pontificia Universidad Javeriana. Email: searango@javeriana.edu.co

3 Médico veterinario de la Universidad de Ciencias Aplicadas y Ambientales UDCA, Bogotá.

4 Mestradp em Producặ Animal. Universidad de Brasilia UnB/ DF. 2009.

5 Especializado en Clínica Médica y Cirugía de Animales Salvajes y Exóticos. Universidad de Castelo Branco UCB, Río de Janeiro, 2008.

6 Especializado en Animales Silvestres: Conservación "no Cerrado e no Pantanal" Sociedad Brasileira de Medicina Veterinaria. Brasil, 2001

\section{REFERENCIAS}

- BOTKIN, D. (1993). Armonías Discordantes. Una ecología para el siglo XXI. Ed. Acento, Madrid, España, p. 10.

- CELY, G. (2007). El Punto de Partida, en: Bioética Global. Ed. Pontificia Universidad Javeriana, Bogotá, Colombia, p. 35; 38. 91-92.

- CURTIS, H. \& BARNES, S. (1994). Biología. 5a edición. Ed. Panamericana, S.A. Buenos Aires, Argentina, p. 38-39. Guías Tropicales de Campo. Colombia. p.22

- DEFlerLL, T. (2003). Primates en Colombia. Ed. Conservación Internacional. Serie de Derechos de los Animales, tomado de: www.dib.unal.co/promocion/etica_deranimal_deranimal.html

- GARZÓN, F. (2002). Del Antropocentrismo al Biocentrismo. Un Nuevo Paradigma Bioético. En: Revista Latinoamericana de Bioética. Ed. Universidad Militar Nueva Granada, Bogotá, Colombia.

- MANCERA, N. \& REYES, O. (2008). Comercio de Fauna Silvestre en Colombia. Revista, Facultad de Agricultura, 61 (2) Universidad Nacional. Medellín, Colombia. p. 4618.

- MARCOS, A. (2001). Ética Ambiental. Ed. Universidad de Valladolid, España. Serie Filosofía, p. 67; 89.

- MARGULIS, L. \& DOLAN, M. (2009). Los Inicios de la Vida. Ed. Universitat de València, España, p. 31.

- SINGER, P. (1999). Liberación Animal. Ed. Trotta, Madrid, España. P. 48.

www.minambiente.gov.co/contenido/contenido_imprimirasp $x$ ?cat $\mid \mathrm{D}=672$ \&con $\mid \mathrm{D}=1930$ \&pag $\mid \mathrm{D}=142$

www.humboldt.org.co/lauh/historico/item/304-esta-semanase-lanza-campa\%C3\%B1a-contra-el-tr 